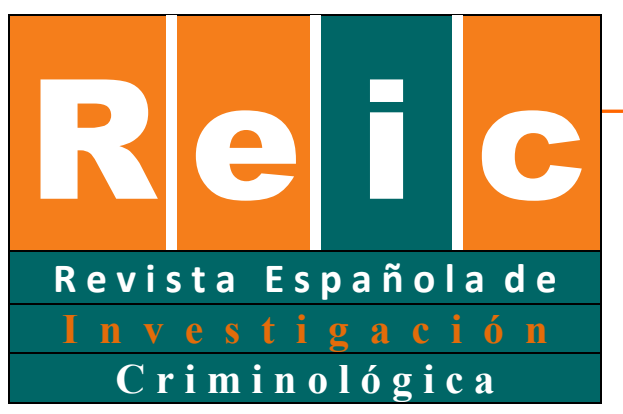

Villacampa \& Torres

\title{
El matrimonio forzado en España. Una aproximación empírica
}

\section{Forced marriage in Spain. An empirical approach}

\author{
Carolina Villacampa ${ }^{1}$ (D) \\ Universitat de Lleida \\ Núria Torres iD \\ Universitat Rovira i Virgili
}

\begin{abstract}
RESUMEN
El matrimonio forzado ha pasado de ser percibido como una práctica exclusiva de lugares lejanos o de tiempos remotos a incorporarse al debate político sobre lo que resulta tolerable en la actual sociedad globalizada. Sin embargo, este debate y sus consecuencias en el plano jurídico penal se desarrollan sin un conocimiento científico suficiente sobre la realidad de este fenómeno en el mundo occidental y en España. El trabajo consiste en un estudio empírico en el que han participado 150 entidades asistenciales, 62 de las cuales han confirmado tener conocimiento de víctimas de matrimonio forzado y han proporcionado información concreta en relación con 57 víctimas identificadas. El análisis de la información proporcionada por las entidades permite contribuir al conocimiento sobre las experiencias de victimización de estas personas, sobre los mecanismos empleados para doblegar la voluntad de las víctimas y sobre sus características en el momento de ser victimizadas y cuando acuden a las entidades.
\end{abstract}

Palabras clave: matrimonio forzado, víctimas, entidades asistenciales, dinámica

\footnotetext{
${ }^{1}$ La correspondencia debe dirigirse a: Carolina Villacampa Estiarte. Departamento de Derecho Público. Universitat de Lleida. C/ Jaume II, 73. 25001 Lleida. cvillacampa@dpub.udl.cat. 


\begin{abstract}
Forced marriage has gone from being perceived as an exclusive practice in distant places or remote times to being incorporated into the political debate on what is tolerable in today's globalized society. However, this debate and its consequences in criminal law are taking place without sufficient scientific knowledge of this reality and of the need to define it in relation to other related practices such as arranged marriage. This paper presents the results of an empirical study in which 150 assistance entities have participated reporting their knowledge of the victims of forced marriage and the dynamics of the commission of this phenomenon in Spain. The results allow us to state the existence of persons who have been forced to marry against their will, some of them legally resident in Spain and even nationals, using means to constrain their will.
\end{abstract}

Keywords: forced marriage, victims, support organizations, dynamics

\title{
1. Introducción
}

La falta de una definición consensuada a nivel internacional sobre el alcance del matrimonio forzado no ha impedido la aceptación de esta denominación para designar aquel que se celebra sin contar con el consentimiento de uno o ambos contrayentes. Organizaciones internacionales y ONGs han denunciado la práctica del matrimonio forzado, de forma muy especial cuando afecta a menores de edad (UNICEF, 2001, 2008, 2014).

En estos últimos años, investigaciones desarrolladas en algunos países de nuestro entorno han constatado que se trata de un fenómeno que, aun cuando mayoritariamente asociado a prácticas propias de otros tiempos y lugares, puede ir en alza también en el denominado mundo occidental. La globalización y las migraciones pueden haber contribuido a la reproducción en Europa y en otros territorios del mundo occidental de patrones de conducta importados desde las comunidades de origen (Philipps \& Dustin, 2004; Martínez \& Lee, 2004; Chantler, Gargoli \& Hester, 2009). Quienes han experimentado un proceso migratorio se hallan con frecuencia en la encrucijada entre la modernidad que impone el contexto occidental en el que residen y los valores tradicionales que, como el honor, el respeto y el acatamiento de las decisiones familiares, algunos miembros de la comunidad se afanan en mantener de forma incluso más férrea que en los territorios de origen (Gangoli, McCarry \& Razaz, 2009). 
Aun cuando la principal aproximación al matrimonio forzado ha sido en tanto que atentado contra los derechos humanos por la vulneración de la libertad individual, los efectos de esta práctica tienen una más amplia dimensión como factor vinculado a situaciones de violencia doméstica, violencia de género, prácticas tradicionales perjudiciales y formas de servidumbre y esclavitud que, sin duda, deben condicionar la estrategia preventiva y la protección de las víctimas (Gangoli, Chantler, Hester \& Singleton, 2011; Gill \& Anitha, 2011; Torres, 2015). En este sentido, el emprendimiento de cualquier forma de intervención dirigida a detectar, asistir y proteger a las víctimas del matrimonio forzado requiere, además de una comprensión conceptual del fenómeno, de un análisis empírico sobre la realidad del mismo.

La complejidad para analizar el alcance cuantitativo de las prácticas de matrimonio forzado deriva del hecho de que se perpetra la mayoría de las veces en el ámbito doméstico o familiar, vinculado frecuentemente a formas de arreglo o pacto matrimonial entre miembros de comunidades étnicas o culturales minoritarias, más reticentes a acudir a los mecanismos del sistema de control formal, contribuyendo a agravar la situación de desconocimiento general sobre el alcance de estas prácticas. La mayor atención que en estos últimos años se ha prestado al matrimonio forzado y al matrimonio infantil ha alentado el desarrollo de investigaciones ya por parte de organizaciones internacionales, ya impulsadas en el ámbito nacional por organizaciones no gubernamentales y de carácter asistencial. Aun cuando tales datos deben acogerse con prudencia dada la dificultad para el cómputo de la práctica, resultan lo suficientemente reveladores sobre la realidad del fenómeno. Así, entre los actualmente disponibles a nivel internacional destaca el informe emitido en el año 2014 por UNICEF que aportaba cifras reveladoras sobre la incidencia del matrimonio infantil a nivel mundial (UNICEF, 2014) y apuntaba a una escasa proporción, aun cuando cierta, de supuestos cometidos en países occidentales. A nivel europeo, destaca la labor desarrollada en el Reino Unido por la Forced Marriage Unit (FMU), creada en 2005, y dependiente del Home Office y del Foreign and Commonwealth Office. Desde el año 2012, la FMU ha prestado apoyo a entre 1200 y 1400 casos anualmente, y en concreto, en el año 2017, las acciones se elevaron a 1196 intervenciones por posible matrimonio forzado, de entre las cuales destaca la elevada presencia de menores (29.7\%) y mujeres y niñas (77.8\%), así como la diversidad en la 
procedencia de las víctimas identificadas (de hasta 90 países distintos). También Alemania abordó una evaluación sobre la incidencia del matrimonio forzado a escala nacional (Mirbach, Schaak \& Thiehl, 2011) constatando que en 2008 hasta 3443 niñas y mujeres jóvenes buscaron asesoramiento sobre matrimonio forzado en entidades y organizaciones. Un $60 \%$ de estas mujeres manifestaron haber sido amenazadas con la celebración del matrimonio y un $40 \%$ acudían en busca de ayuda una vez ya consumado. El 70\% tenían menos de 21 años y un 30\% eran menores. En la mitad de los casos las víctimas habían sido trasladadas al extranjero. Por su parte, la organización alemana Terre des Femmes, especializada en el apoyo a víctimas de matrimonio forzado, prestó en 2012 información a un total de 118 niñas y jóvenes sobre esta materia, de las cuales 82 habían sido amenazadas con un matrimonio, y en 36 casos ya habían sido forzadas. Aun cuando en Italia, la incidencia de los matrimonios forzados ha sido menos estudiada, la investigación desarrollada por la organización Associazione Trama di Terre en el año 2009 en la región Emilia-Romagna (Trama di Terre, 2014), detectó un total de 33 casos de matrimonio forzado en la zonade los que únicamente tres correspondían a hombres, siendo todas las víctimas identificadas de origen extranjero, habiéndose efectivamente celebrado el matrimonio en 20 de los casos y en 11 de estos en el extranjero aunque la familia de la novia residiera en Italia. A diferencia de los trabajos citados, que reflejan las cifras de asistencias proporcionadas por entidades y organizaciones prestadoras de servicios, el estudio dirigido por Hamel en Francia en año 2011 (Hamel, 2011) analiza y compara el grado de consentimiento de las mujeres en el momento de su primera unión en pareja, constatándose una mayor proporción de matrimonios no consentidos entre mujeres migrantes de entre 51 y 60 años (9\%) y muy inferior en la franja de edad de 26 a 30 años (1 y 3\% respectivamente), lo que lleva a los autores a concluir que el matrimonio forzado es una práctica en claro declive en este país. Finalmente, también en los Estados Unidos se desarrolló una extensa investigación en la que 500 entidades asistenciales dieron cuenta de hasta 3000 casos en los que durante los dos años previos a la encuesta constataron o sospecharon de un matrimonio forzado entre sus usuarios (Tahirih Justice Center, 2011).

En lo que a España respecta, se ha contado con datos muy limitados, procedentes fundamentalmente de algunos registros policiales en Cataluña y, más recientemente, del 
proyecto Matrifor sobre trata de seres humanos y matrimonio forzado (Igareda, Barcons, Lotti \& Leye, 2016). En todo caso, la falta de información fidedigna sobre la realidad de este fenómeno no fue impedimento para que el legislador español decidiera tipificar por LO 1/2015 el delito de matrimonio forzado. La incriminación supuso la adhesión al mandato contenido en el art. 37 del Convenio de Estambul de 2011 y la adaptación prácticamente mimética del precepto en el art. 172bis CP. El resultado no ha sido particularmente bien recibido por la doctrina, que ha puesto de manifiesto tanto el carácter privilegiante de este delito respecto de otros tipos ya existentes en el Código penal (Igareda, 2015; Maqueda, 2016; Trapero, 2016) como lo inadecuado del recurso prioritario al Derecho penal a pesar de las dificultades de intervención en un ámbito muy vinculado a lo familiar y lo comunitario y sin previsión de despliegue de otras medidas de carácter tuitivo (Torres, 2015; Villacampa, 2018). Además, y a diferencia de lo que se aprecia en el ámbito internacional, el legislador ha reconocido también la dimensión del matrimonio forzado en el ámbito de la trata de seres humanos, incluyéndolo como una de las finalidades de explotación previstas en el art. 177bis $\mathrm{CP}$, con posibilidad de aplicación de penas mucho más severas que las previstas en el art. 172bis CP.

\section{Objetivos}

El principal objetivo de esta investigación consistía en determinar la existencia de matrimonios forzados en España a través de la confirmación de que entidades sociales o asistenciales hubiesen entrado en contacto con víctimas actuales o potenciales de este fenómeno. Junto a este objetivo principal, también constituían objetivos de esta investigación determinar, a partir de la información proporcionada por las entidades que han tenido contacto con víctimas de matrimonio forzado, los colectivos en riesgo de victimización ya por razones de género, de edad, de nacionalidad u otros caracteres. En segundo término, se

perseguía conocer las dinámicas de victimización que comporta el matrimonio forzado, fundamentalmente mediante la identificación de los mecanismos a través de los cuales se ejerce presión sobre las víctimas, así como el lugar donde se contrae. Finalmente, se pretendía establecer en qué condiciones las entidades conocen de este tipo de casos, atendiendo tanto 
al ámbito de actividad de las entidades conocedoras, como a las circunstancias de tiempo y lugar que acompañan a estos casos en el momento de salir a la luz, y las características de las víctimas cuando estas acuden a las entidades asistenciales.

\section{Metodología}

Con la finalidad de contactar con entidades que pudiesen actuar como fuentes de información, se comenzó elaborando una base de datos de las de ámbito local, autonómico y nacional que se consideró que eventualmente podían entrar en contacto con víctimas de matrimonios forzados que acudiesen a pedirles asesoramiento o asistencia y que ascendió a 518 entidades, lo que constituyó la muestra invitada. La base se obtuvo a partir de un rastreo de páginas web de entidades entre las que se incluían las que prestan servicios de asesoramiento y atención a las víctimas de violencia doméstica y de género y víctimas de trata de seres humanos, oficinas de asistencia a la víctima, asociaciones culturales de inmigrantes y centros educativos de secundaria. Se efectuó una inicial clasificación de dichas entidades en función de que se entendiese que tenían mucha o escasa probabilidad de entrar en contacto con víctimas de matrimonios forzados.

Se empleó pues una técnica de muestreo subjetivo por decisión razonada en que las unidades de la muestra se escogieron en función de sus características de manera racional, esto es, atendiendo a que por el tipo de servicios prestados resultase verosímil que pudiesen haber entrado en contacto con víctimas de matrimonio forzado.

Al mismo tiempo, se confeccionó un cuestionario online mediante el empleo de la plataforma google forms. Puesto que se trataba de un instrumento elaborado específicamente para esta investigación, aun cuando inspirado en los empleados previamente por Sharp (2008), Khanum (2008) o el Tahirih Justice Center (2011), se efectuó una prueba piloto del mismo con una muestra de 10 personas del entorno académico de los investigadores como parte del proceso para garantizar la validez de contenido aparente. La aplicación de esta prueba permitió un ajuste en la redacción de dos de las preguntas. Esta versión mejorada se envió electrónicamente, junto con una carta de presentación sobre la investigación, de manera sucesiva a las organizaciones de la base de datos cada quincena durante cinco meses -entre 
mayo y septiembre de 2016-. Se insistió más con aquellas entidades que los investigadores consideraron que tenían mayor probabilidad de hallar víctimas de matrimonios forzados. Puesto que en el momento en que se diseñó esta investigación no se había constituido el comité ético en la institución en que la misma se llevó a cabo, no pudo recabarse la aprobación de la investigación propuesta por parte del mismo.

Dado que la respuesta al cuestionario online fue poco cuantiosa, al haberse obtenido tan solo 19 respuestas en septiembre de 2016, se decidió modificar la metodología, contactando telefónicamente entre octubre de 2016 y febrero de 2017 con las 499 entidades que no habían respondido a la inicial solicitud online. Una vez que fueron recontactadas por teléfono y se les expuso el contenido de la investigación, remitiéndoles de nuevo el cuestionario online, se consiguió incrementar el número de respuestas a 150, lo que constituye la muestra real de esta investigación.

El cuestionario empleado constaba de tres partes, las dos primeras relativas a la entidad y la tercera que contenía varias fichas sobre posibles víctimas identificadas asistidas por esta. En la primera parte de la encuesta se efectuaban 4 preguntas generales sobre la entidad, relativas a la identificación y ámbito de actuación de la misma, así como con el objeto de saber si los matrimonios forzados constituían un objetivo prioritario en dicha institución. Si la entidad había conocido algún caso de matrimonio forzado, se le pedía que continuase rellenando el cuestionario; en caso contrario, lo finalizaba.

La segunda parte del cuestionario, reservada para entidades que habían tenido conocimiento de algún supuesto de matrimonio forzado, se componía de 5 cuestiones. Se preguntaba acerca del concreto número de casos que recordaban, cómo llegaron los hechos a su conocimiento (si como casos de violencia familiar/de género, directamente como casos de matrimonio forzado, no se sabía o de otro modo), quién los puso en conocimiento de la entidad (si la víctima, algún familiar, amigo, conocido, docente de esta, otro o el encuestado lo desconocía), y si las víctimas identificadas habían contraído ya matrimonio o estaban en riesgo de contraerlo cuando fueron contactadas. Para concluir esta parte se preguntaba a las entidades si recordaban datos concretos sobre alguna o algunas de las víctimas asistidas, solicitándoles que rellenasen la tercera parte del cuestionario en caso afirmativo. 
Esta tercera parte estaba compuesta por fichas individuales de víctimas identificadas; se preveía que cada entidad pudiese cumplimentar un máximo de 3 fichas integradas por 11 cuestiones cada una que deberían proporcionar conocimiento sobre las características de dichas víctimas en el momento de ser sometidas a un proceso de matrimonio forzado, así como en el momento de acudir a la entidad. No se dieron indicaciones específicas a las entidades para la selección de víctimas sobre las que informar y únicamente se estableció un límite cuantitativo de fichas con el fin de no sobrecargar a la entidad. En tales fichas se preguntaba acerca del sexo de las víctimas identificadas, la edad en el momento de contraer o ser ofrecidas en matrimonio y en el momento de intervención de la entidad, si tenían hijos en el momento de intervenir la entidad y la nacionalidad de la víctima identificada en caso de no ser española. Junto a estas, se incluían las siguientes cuestiones con las opciones de respuesta indicadas:

- Estado civil de la víctima en el momento de intervención de esta entidad. Opciones de respuesta: 1. Soltera, 2. Casada, 3. Separada, 4. Divorciada, 5. Viuda, 6. No lo sabe.

- En el momento de intervención de esta entidad ¿cuál era la situación legal de la víctima? Posibles respuestas: 1. Nacional española, 2. Residente legal, 3. Extranjera sin residencia legal, 4. Refugiada o asilada política, 5. No lo sabe, 6. Otro.

- Comunidad o etnia de la víctima. Posibles respuestas: 1. Magrebí, 2. Subsahariana, 3. Sudeste asiático, 4. Asia central, 5. América del Sur, 6. Europa del Este, 7. Europa Occidental, 8. Etnia gitana, 9. No lo sabe, 10. Otro.

- Religión de la víctima. Posibles respuestas: 1. Católica, 2. Protestante, 3. Ortodoxa, 4. Musulmana, 5. Hindú, 6. Judía, 7. No lo sabe, 8. Otro.

- ¿Cuáles han sido los medios empleados para forzar a la víctima a contraer matrimonio? Cuestión que admitía respuesta múltiple. Opciones: 1. Violencia, 2. Amenazas/intimidación, 3. Presión familiar, 4. Apego a la tradición/cultura, 5. Engaño, 6. No lo sabe, 7. Otro.

- Lugar donde se celebró o estaba previsto celebrar el matrimonio. Respuestas incluidas en el cuestionario: 1. En territorio español, 2. En otro país de la UE, 3. 
En el país de origen de la familia de la víctima (si no es España o la UE), 4. En el país de origen de la familia del contrayente (si no es ninguno de los anteriores), 5. No lo sabe, 6. Otro.

Recopiladas las respuestas fueron tratadas, una vez anonimizadas, empleando el programa estadístico SPSS versión 24.

\section{Muestra}

La muestra invitada de 518 quedó concretada en una muestra real de 150 entidades asistenciales, sociales y docentes que finalmente respondieron al cuestionario online.

Por su ubicación territorial, casi dos terceras partes de estas entidades tienen su sede en Catalunya, puesto que el envío de cuestionarios a esta Comunidad fue más exhaustivo, si bien una tercera parte de estas estaban ubicadas en otras Comunidades Autónomas (vid. Figura 1). Entre las ubicadas en Catalunya, junto a las que tenían ámbito autonómico (n=3),

por provincias, la mayor parte pertenecían a Barcelona $(n=38)$, seguidas de Lleida $(n=24)$, Tarragona $(n=20)$ y Girona $(n=14)$.

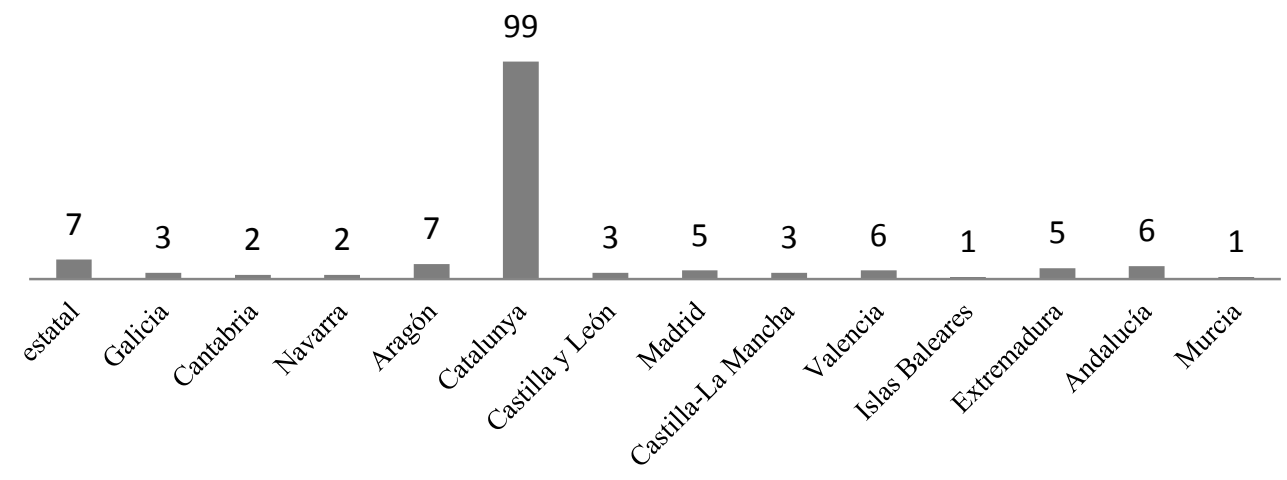

Figura 1: Ámbito territorial de las entidades por CCAA 
En relación con el tipo de actividad desarrollada, los ámbitos de actuación de las entidades (Figura 2) mayoritariamente se correspondían con las que prestan asistencia a víctimas de violencia de género y familiar $(n=74)$, asistencia a víctimas en general $(n=51)$, a víctimas de trata de seres humanos $(n=34)$ y de matrimonios forzados $(n=32)$, así como asistencia a inmigrantes $(n=34)$. De toda la muestra real, 39 entidades $(30.5 \%)$ tenían el matrimonio forzado como objeto prioritario de la entidad, mientras 84 (65.6\%) no tenían dicho fenómeno entre sus prioridades.

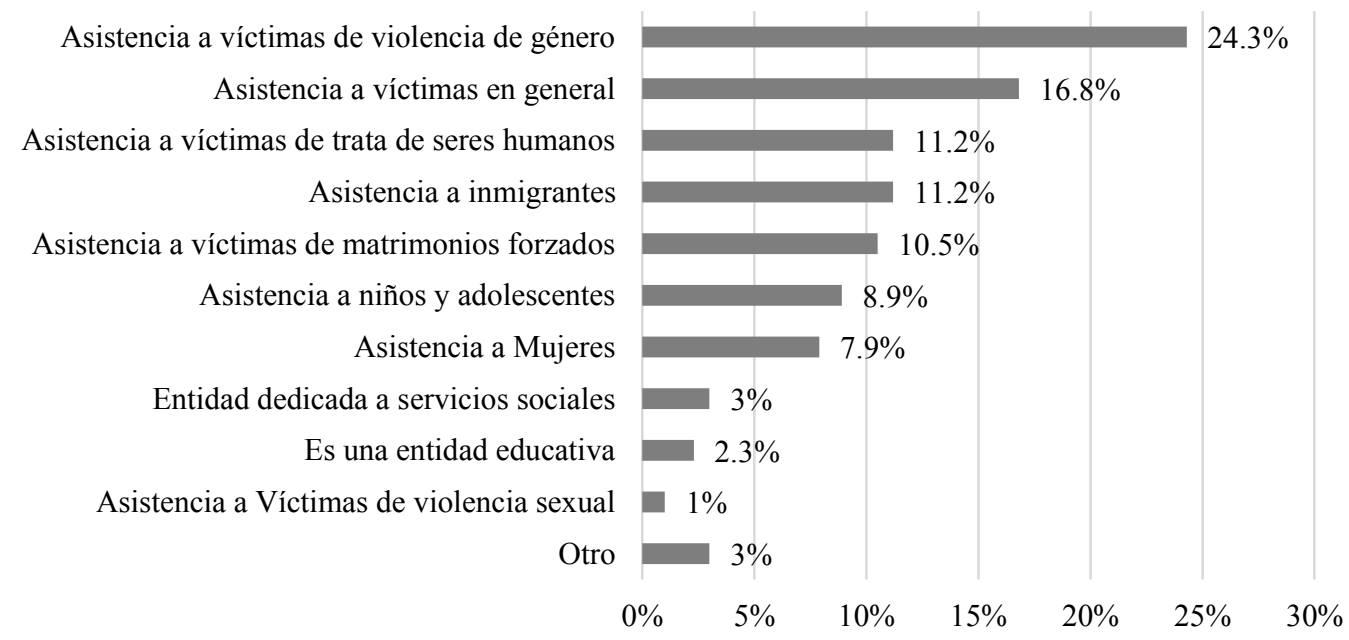

Figura 2: Ámbito de actuación de la entidad

Finalmente, respecto del grado de cumplimentación del cuestionario de las integrantes de la muestra, el 58\% $(\mathrm{n}=88)$ respondieron únicamente los datos básicos referidos a la entidad e indicaron que no habían tratado a víctimas de matrimonios forzados. El 42\% $(\mathrm{n}=62)$ continuó adelante con la realización del cuestionario, puesto que habían detectado víctimas de este fenómeno. De estas entidades, un 13\% $(\mathrm{n}=19)$ cumplimentaron solo hasta la segunda parte del cuestionario, sin llegar a rellenar fichas de víctimas, mientras un 29\% $(n=43)$ completaron el cuestionario, cumplimentando 57 fichas correspondientes a víctimas concretas.

Por lo tanto, junto a la muestra de 150 entidades, la investigación se nutre también de una segunda fuente de información configurada por la muestra de 57 fichas de víctimas 
identificadas remitidas por 43 de las 62 entidades que confirmaron haber entrado en contacto con víctimas y que, tras finalizar la segunda parte del cuestionario, rellenaron y remitieron una o varias fichas.

\section{Resultados}

El hecho de que 62 de las entidades que rellenaron el cuestionario afirmaran que habían detectado a víctimas de matrimonios forzados, confirma que el matrimonio forzado constituye un fenómeno que se produce también en España. En esto, el presente estudio resulta coincidente con anteriores investigaciones que en el contexto comparado han constatado la existencia de víctimas de este proceso en el primer mundo (FMU, 2016; FRA, 2014; Hamel, 2011; Hester et al. 2007; Kazimirski, 2009; Mirbach et al., 2011; Tahirih Justice Center, 2011; UNICEF, 2014). Además, las 57 fichas de víctimas identificadas remitidas por las entidades permiten una aproximación a las características de las víctimas identificadas de este fenómeno.

\subsection{Características sociodemográficas de las víctimas identificadas de matrimonios forzados}

En cuanto al sexo, se constata que todas las víctimas identificadas por las entidades y de las que se remitió información en las fichas previstas en el apartado tercero del cuestionario son mujeres. Ninguna de las entidades reveló haber asistido a muchachos que hubieran sido víctimas de este tipo de procesos.

Respecto de la edad en el momento de contraer o ser prometida en matrimonio, en la Figura 3 se muestra una comparativa entre la edad en ese momento y la que las víctimas identificadas tenían al intervenir la entidad que evidencia cómo las víctimas eran más jóvenes en el momento de contraer o ser prometidas en matrimonio que en el momento de buscar asistencia. Los resultados de la investigación revelan que el 33,9\% de las menores de edad en el momento de contraer o ser prometida en matrimonio está compuesto por un $1,8 \%$ de 
víctimas menores de 15 años y un 32,1\% de víctimas menores de entre 16 y 17 años, siendo el 76,8\% de las víctimas no mayores de 21 años.

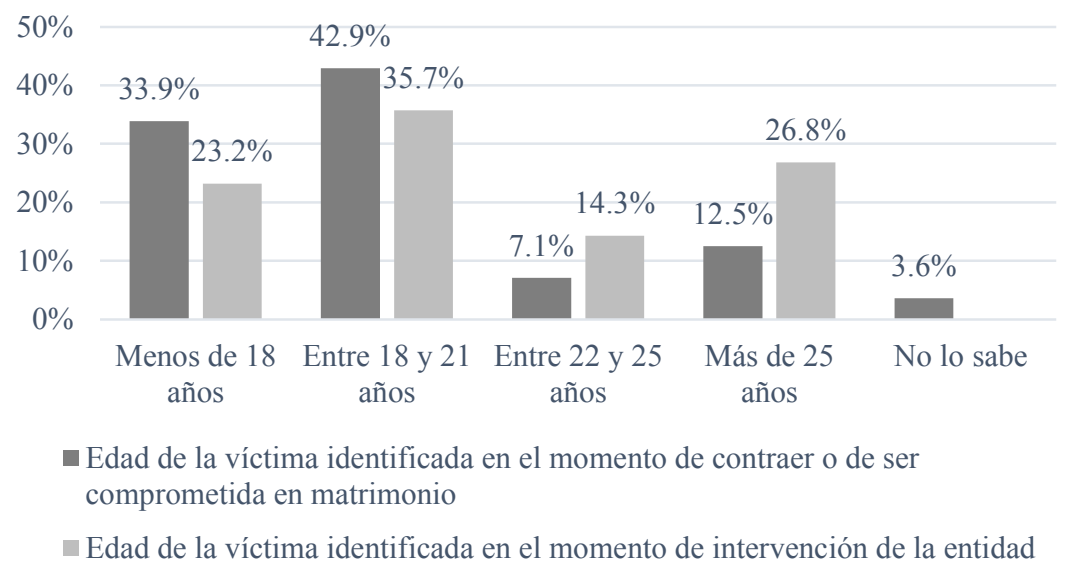

Figura 3: Comparativa edades en el momento de contraer o ser comprometida en matrimonio y en el momento de intervención de la entidad

Por nacionalidades, junto al porcentaje de víctimas identificadas de nacionalidad desconocida, la más mayoritaria es la nacionalidad marroquí, seguida por un nada desdeñable porcentaje de víctimas de nacionalidad española y a mayor distancia pakistaníes y gambianas (vid. figura 4)

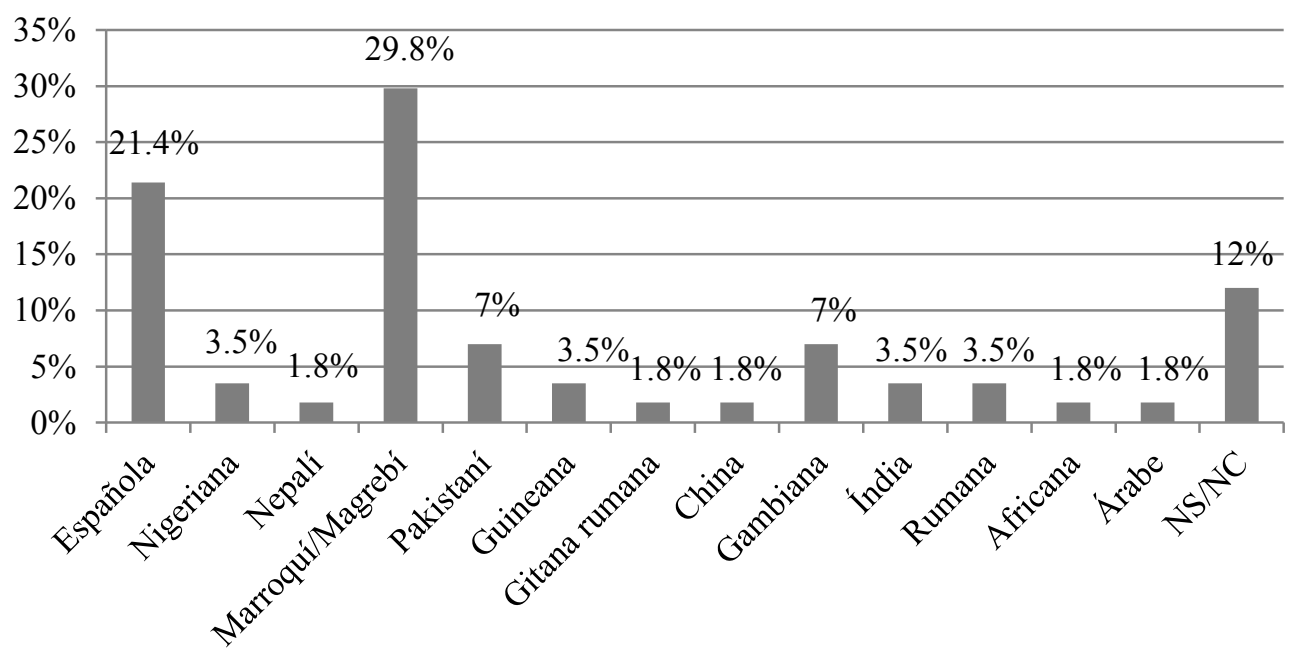

Figura 4: Nacionalidad de las víctimas identificadas 
Por comunidades-etnias, la mayoría de las víctimas identificadas proceden del Magreb (42.9\%), África Subsahariana (25\%) y Asia Central (8.9\%), aunque el 7.1\% eran gitanas (figura 5). La comunidad-etnia a la que pertenece la víctima identificada, sin embargo, no sirve para explicar la edad en la que esta contrae o es prometida en matrimonio, puesto que la relación entre ambas variables no resultó estadísticamente significativa ( $\chi 2$ (27, $N=57)=26.88 ; \rho=.470 ; \Phi=.419)$, evidenciándose, al menos en la comunidad magrebí y subsahariana, que las víctimas identificadas son mayoritariamente dadas en matrimonio cuando son mayores de edad, si bien ese patrón no resulta tan claro en el caso de Asia Central o la etnia gitana.

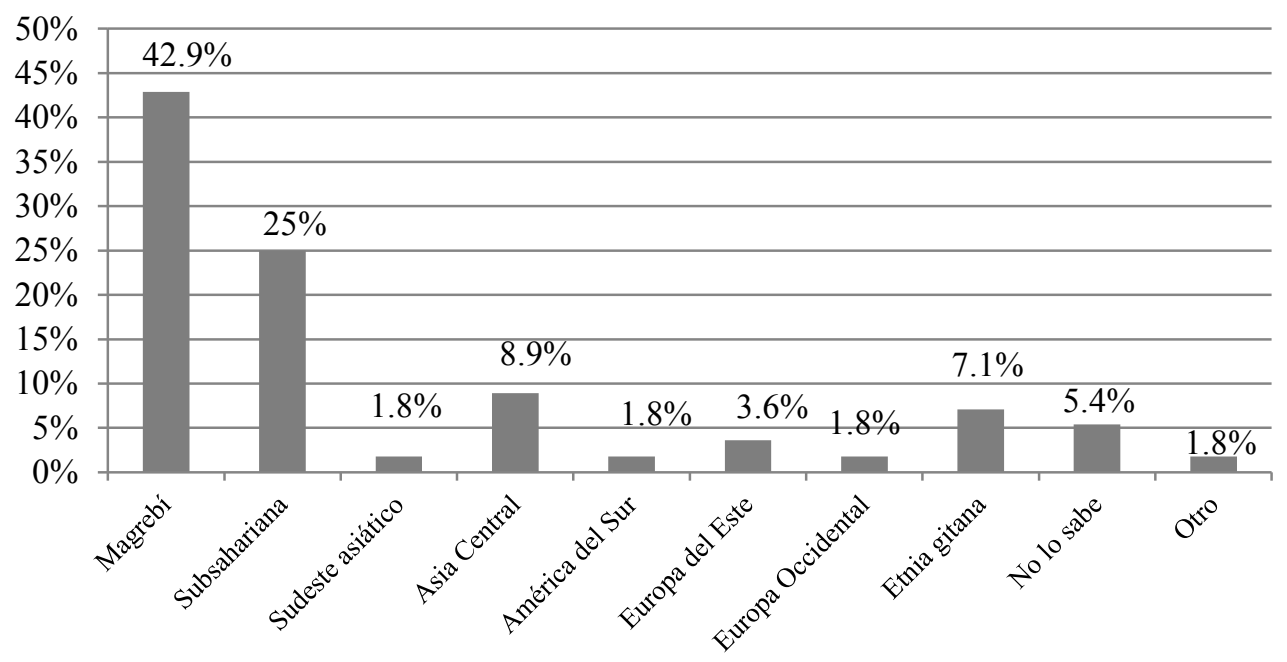

Figura 5: Comunidad o etnia de la víctima identificada

Respecto de la religión que las entidades indican que las víctimas identificadas practican, la abrumadora mayoría refiere la religión musulmana, aun cuando no resulta desdeñable el porcentaje de víctimas que no se identifican con una religión (vid. Figura 6). El porcentaje de víctimas católicas se queda en un 3.6\%, siendo todavía más testimonial el correspondiente a víctimas de religión sikh, ortodoxa o hindú. Tampoco se observa la existencia de relación estadísticamente significativa entre la religión de la víctima y la edad a la que esta fue prometida o dada en matrimonio $(\chi 2(15, N=57)=20.17 ; \rho=.165 ; \Phi=.350)$.

\section{Revista Española de Investigación Criminológica}




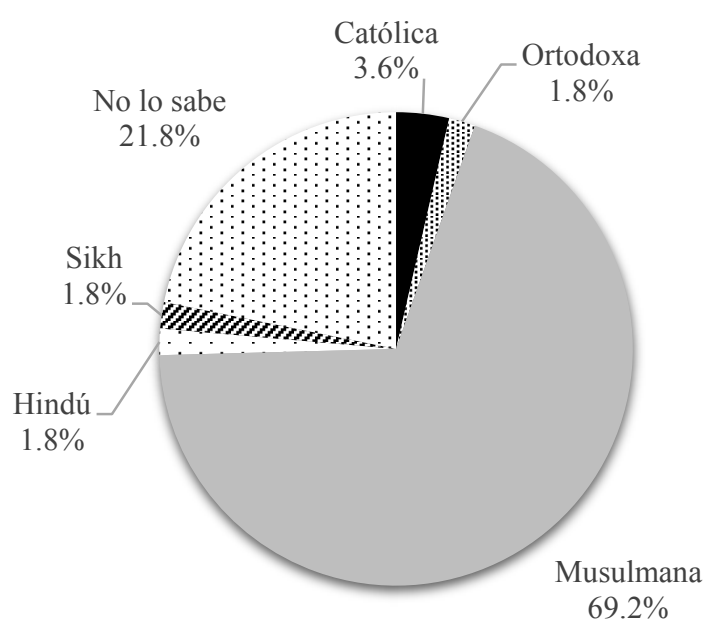

Figura 6: Religión de la víctima identificada

Realizada una correlación de variables para determinar cuáles son las que tienen más relevancia para explicar la victimización por matrimonios forzados, se observa como las relativas a la nacionalidad, la religión y la comunidad/etnia tienen mayor peso explicativo, aun cuando a este respecto debe advertirse que no se ha podido controlar los sesgos de los informadores al seleccionar los casos.

\subsection{Dinámica de la victimización}

Se ha indicado cómo el proceso de victimización por matrimonio forzado, que pretende describirse en este estudio, atiende a los medios empleados para forzar a la víctima a contraer matrimonio, de un lado, y al lugar donde se celebró o estaba previsto celebrar el matrimonio, de otro.

Respecto de los medios empleados para forzar a las víctimas identificadas a contraer, la estadística descriptiva muestra (Figura 7) que los medios más empleados son la presión familiar y el apego a la tradición o la cultura de la víctima, siendo menos habitual el empleo de amenaza o intimidación y todavía menos el recurso al engaño o la violencia. Esto es, resulta más habitual recurrir a mecanismos sutiles para mover la voluntad de las víctimas que 
no aparecen contemplados como medios comisivos en el delito de matrimonio forzado del art. 172 bis CP que recurrir a medios -como la amenaza/intimidación, el engaño o la violencia- que sí contempla el tipo delictivo.

Esta investigación no ha revelado una relación estadísticamente significativa entre las variables medios contemplados en el Código penal -en adelante, CP-y edad de la víctima al contraer o ser prometida en matrimonio $(\chi 2(3, N=57)=2.494 ; \rho=.476 ; \Phi=.211)$. Sin embargo, agrupando los medios entre aquellos que contempla el CP en el delito de matrimonios forzados y los que no contempla, se observa como en las víctimas identificadas de menos de 18 años se recurrió a los medios con relevancia penal en 10 casos, mientras que en las que superaban la mayoría de edad se hizo en 20 casos. Con todo, en todas las franjas de edad se recurre más a mecanismos más sutiles que drásticos.

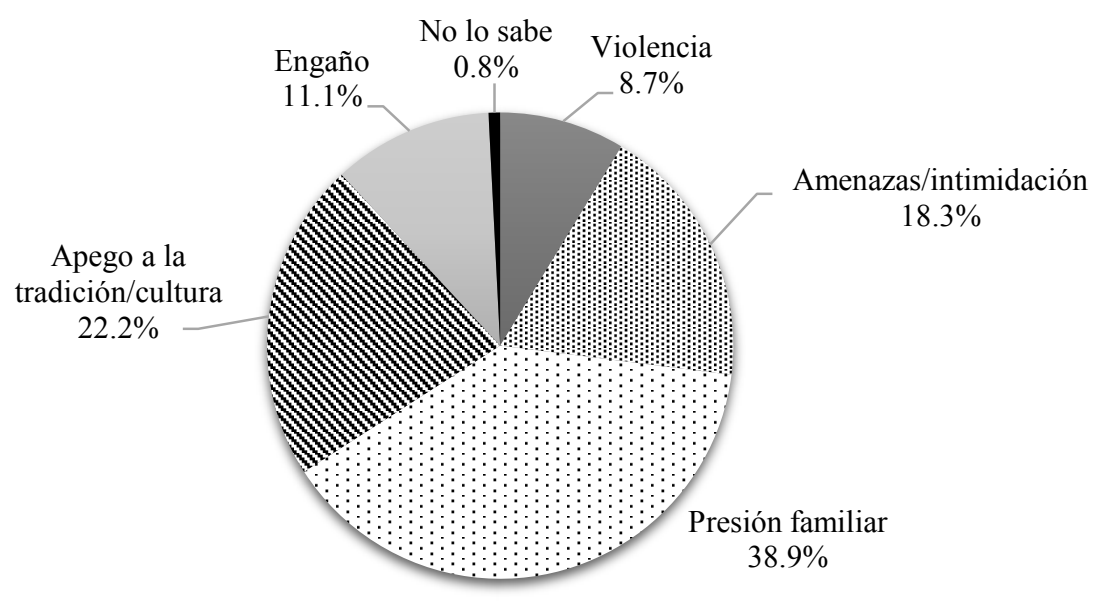

Figura 7: Medios empleados para forzar a la víctima identificada a contraer matrimonio

Los medios usados tampoco se vieron mediatizados por la nacionalidad de la víctima o por la comunidad-etnia a la que esta pertenecía. En tal sentido, no se ha revelado la existencia de una relación estadísticamente significativa entre las variables nacionalidad o comunidad de la víctima identificada y la referida a que los medios empleados para obligarla a contraer puedan entenderse constitutivos de violencia o intimidación ${ }^{2}$. Precisamente, los

\footnotetext{
2 Valores estadísticos para la correspondencia entre variables "medios contemplados en el CP" con variables: "nacionalidad de la víctima" $(\chi 2(12, N=57)=20.43 ; \rho=.059 ; \Phi=.639)$ "comunidad: magrebí" $(\chi 2(1, N=57)$

Revista Española de Investigación Criminológica 
medios más insidiosos -violencia o intimidación- se han empleado con víctimas de nacionalidad española, en que el medio comisivo más usado ha sido la amenaza, por contraposición a lo sucedido en nacionalidades como la marroquí, en que lo habitual ha sido el recurso a la presión familiar o al apego a la tradición, así como en la comunidad subsahariana donde, sin embargo, el recurso a medios más insidiosos no ha sido tan limitado. Tales resultados, sin tener tampoco relevancia estadística significativa, se confirman cruzando las variables situación legal de la víctima, por un lado, y medios empleados, por otro, en que nuevamente el recurso a medios como la violencia o la intimidación se evidencia más en los supuestos de víctima nacional española (11 casos de recurso a medios incluidos en el CP frente a 9 que no) o residente legal en España que en supuestos de ilegalidad en la residencia.

Tampoco la religión de la víctima identificada sirve para explicar los medios empleados en la dinámica del matrimonio forzado. Nuevamente nos encontramos frente a una situación en la que no podemos hablar de relevancia estadística de la relación entre las variables medios contemplados en el CP y religión de la víctima $(\chi 2(5, N=57)=5.344$; $\rho=.375 ; \Phi=.312$ ). Sin embargo, según los datos con que se cuenta, las víctimas de religión musulmana han sido dirigidas a la situación empleando más habitualmente medios no contemplados que contemplados en el $\mathrm{CP}$, las víctimas de religión católica e hindú empleando exclusivamente medios no contemplados en el CP y las de religión ortodoxa y sikh lo mismo los contemplados que los que no.

Respecto del lugar donde se celebró o estaba previsto celebrar el matrimonio, lo más habitual es el desplazamiento al país de origen de la familia de la víctima para contraer, aunque en un $30.4 \%$ de los casos la celebración se produjo o estaba previsto que se produjese en territorio español (Figura 8).

$=2.194 ; \rho=.139 ; \Phi=.203)$, "comunidad: subsahariana" $(\chi 2(1, N=57)=1.002 ; \rho=.317 ; \Phi=.137)$, "comunidad: Asia Central" $(\chi 2(1, N=57)=.365 ; \rho=.546 ; \Phi=.083)$, "comunidad: etnia gitana" $(\chi 2(1, N=57)=.014 ; \rho=.906$; $\Phi=.016)$. 


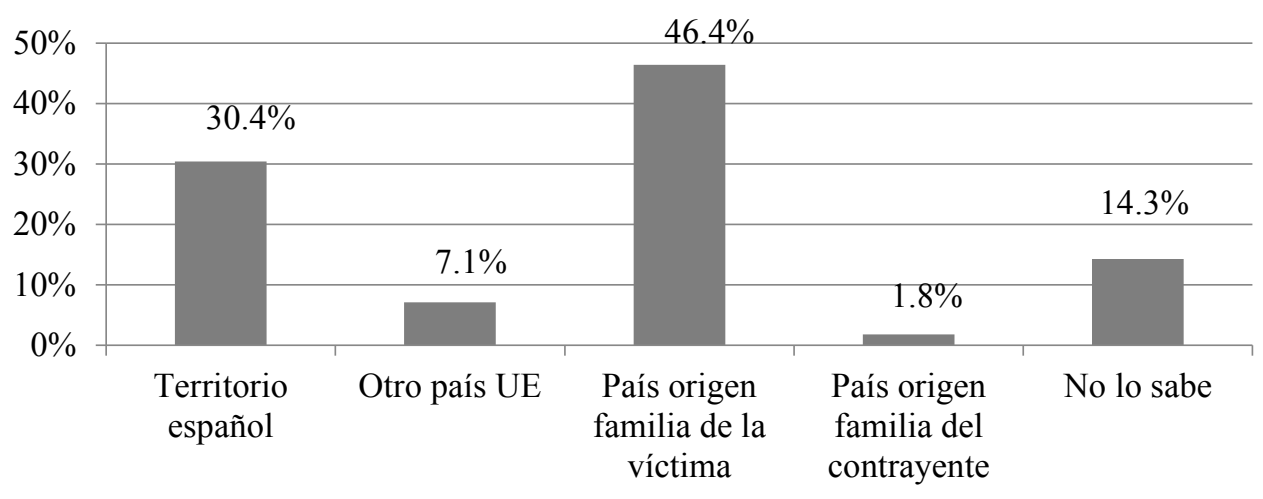

Figura 8: Lugar dónde se celebró o estaba previsto celebrar el matrimonio

Para explicar este extremo no ha resultado ser estadísticamente significativa la correlación establecida entre esta variable y la relativa a la edad de la víctima al contraer ( $\chi 2$ $(12, N=57)=7.622 ; \rho=.814 ; \Phi=.213)$, su situación legal $(\chi 2(12, N=57)=13.92 ; \rho=.306$; $\Phi=.288)$, su nacionalidad $(\chi 2(48, N=57)=59.06 ; \rho=.132 ; \Phi=.543)$, su comunidad-etnia ( $\chi^{2}$ $(36, N=57)=28.63 ; \rho=.804 ; \Phi=.375)$ o la religión que profesa la víctima $(\chi 2(20, N=57)$ $=21.30 ; \rho=.439 ; \Phi=.304)$. Sin embargo, los datos muestran que las víctimas identificadas de más edad tienden a casarse más en España u otro país de la UE, mientras que las menores lo hacen más en el país de origen de su familia. Del mismo modo, junto a las víctimas identificadas de nacionalidad española, que lógicamente tienden a casarse más habitualmente en territorio español, también las que tienen residencia legal aquí lo hacen, de forma que son las que carecen de dicha residencia las que tienden más a ir a su país de origen a contraer matrimonio. Por comunidades, las magrebíes y las que proceden del África subsahariana tienden a casarse más en su país de origen, no así las del Asia Central, que se desposan por igual en España que en su país de origen, o las de etnia gitana, que mayoritariamente contraen en España. Por nacionalidades, al margen de la española, las marroquíes y guineanas tienden a casarse en el país de procedencia y las gambianas en España, aunque el escaso número de víctimas en cada una de estas categorías no permite establecer patrones. 


\subsection{Condiciones en las que estos procesos de victimización afloran}

El último de los objetivos de esta investigación consistía en determinar de qué modo este tipo de procesos llegaban a conocimiento de las entidades, tanto atendiendo a las características de las organizaciones más proclives a la identificación de las víctimas, como atendiendo a las circunstancias de tiempo y lugar en que tales casos afloran y a la concreta situación personal de la víctima en el momento de acudir a la entidad.

\section{Características de las entidades}

Respecto de las entidades, las que han dado cuenta de un mayor número de supuestos de matrimonios forzados han sido (vid. Figura 9), por el siguiente orden, las dedicadas a la asistencia a víctimas de violencia familiar y violencia de género (ámbito de actuación del $65 \%$ de las entidades que han conocido casos), a víctimas de trata de seres humanos (ámbito del $38.3 \%$ de estas entidades) y a víctimas de matrimonios forzados (35\%). En los tres casos, la correlación de las variables ámbito de actividad de la entidad y detección o conocimiento de casos de matrimonios forzados es estadísticamente significativa. Respectivamente, para las entidades que asisten víctimas de violencia de género y familiar $\chi^{2}(2, N=150)=13.62$; $\rho=.001 ; \Phi=.303$, para las que asisten víctimas de trata de seres humanos $\chi 2(2, N=150)$ $=14.45 ; \rho=.001 ; \Phi=.312$ y para las que asisten a víctimas de matrimonios forzados $\chi^{2}$ (2, $N=150)=13.62 ; \rho=.003 ; \Phi=.281$. Se realizó además una regresión logística para determinar qué grado de probabilidad tenía el grupo de entidades con ámbito de actividad relacionado con la asistencia a víctimas de violencia doméstica y de género de detectar víctimas de matrimonios forzados de la que resultó que estas entidades tenían una probabilidad 2.597 veces mayor de identificarlas que una entidad en cuyo ámbito de actuación no entre esta actividad. 


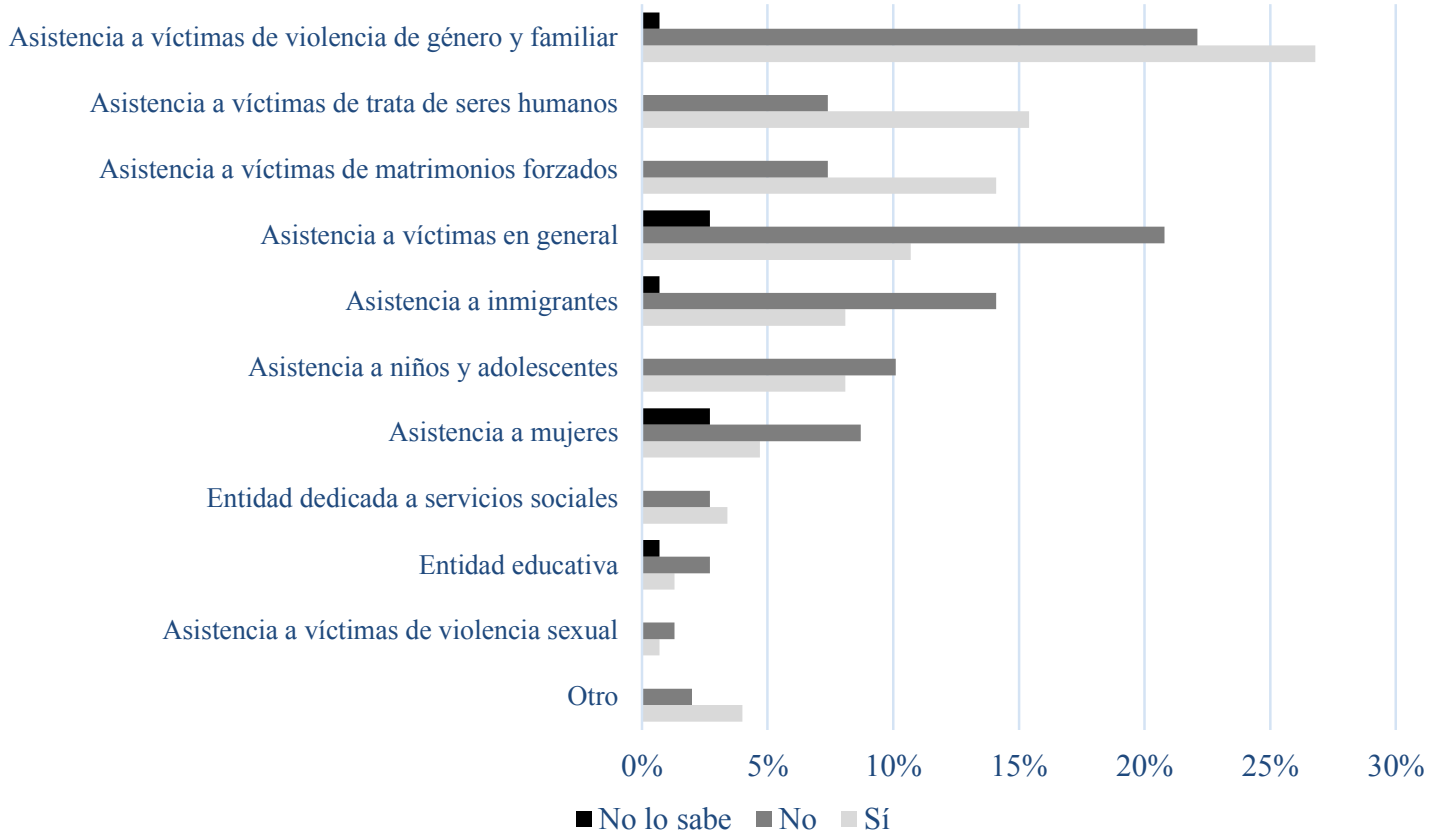

Figura 9: Detección/no detección de víctimas en función del ámbito de actividad de la entidad

También son estas entidades las que han rellenado más fichas de víctimas, como puede observarse en la figura 10.

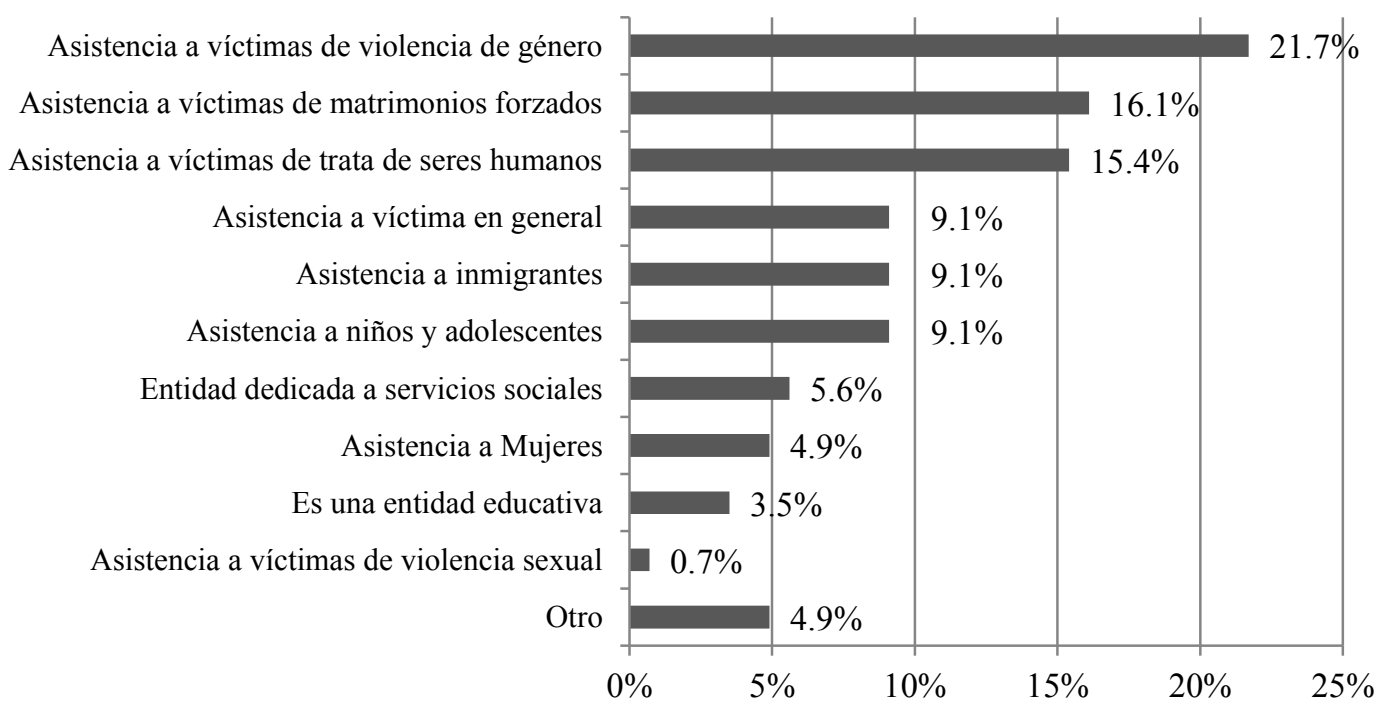

Figura 10: Ámbito de actuación de la entidad que ha rellenado fichas de víctimas 
Sin embargo, que la entidad tenga el matrimonio forzado como objetivo prioritario de actividad no correlaciona positivamente de forma estadísticamente significativa con la circunstancia de conocer más casos $(\chi 2(4, N=150)=11.32 ; \rho=.023 ; \Phi=.211)$. No son las entidades que tienen este fenómeno como objetivo prioritario las que detectan más casos en términos porcentuales (44\%), siendo que las que no tienen este fenómeno como objetivo prioritario de la entidad lo han hecho en el 54\% de ellos. No obstante, según resulta de la regresión logística realizada al efecto, una entidad que tiene como objetivo prioritario los matrimonios forzados tiene 2.823 veces más de probabilidad de conocer supuestos de matrimonio forzado que la que no lo tiene. Además, que el matrimonio forzado sea objetivo prioritario de la entidad sí explica la cantidad de casos que recuerda haber asistido la institución, dado que fueron precisamente estas entidades las que recordaron haber asistido por encima de 5 casos de matrimonios forzados (segunda parte del cuestionario), lo que además resulta coherente con que fuesen precisamente estas entidades las que rellenaran más fichas de víctimas (el $51.8 \%$ de las entidades que los rellenaron tenían como objetivo prioritario el matrimonio forzado).

Con ser determinante para explicar su capacidad para detectar casos, el ámbito de actividad de las entidades analizadas no ha resultado demasiado relevante para explicar cómo llegan los hechos a conocimiento de la misma, si como casos de matrimonios forzados, como casos de violencia de familiar o de género o de otro tipo (sobre esto vid. Figura 11). El análisis bivariante ha mostrado que a las entidades más efectivas en la detección de los casos estos les llegan más habitualmente como supuestos de violencia familiar o de género. Tal hallazgo resulta comprensible para las entidades dedicadas a la asistencia a víctimas de violencia familiar y de género, pero también es así para las entidades dedicadas a asistir a víctimas de matrimonios forzados y de trata de seres humanos. Sin embargo, en el caso de las entidades dedicadas a la asistencia a inmigrantes, aun cuando no alcance a tener significación estadística, los casos les llegan más directamente como supuestos de matrimonios forzados que como casos de violencia de género $(\chi 2(1, N=150)=7.42 ; \rho=.006 ; \Phi=.355)$, de manera semejante a lo que sucede en las dedicadas a servicios sociales $(\chi 2(1, N=150)=2.98 ; \rho=.084$; $\Phi=.225$ ) o a la asistencia a niños $(\chi 2(1, N=150)=1.61 ; \rho=.204 ; \Phi=.165)$. 


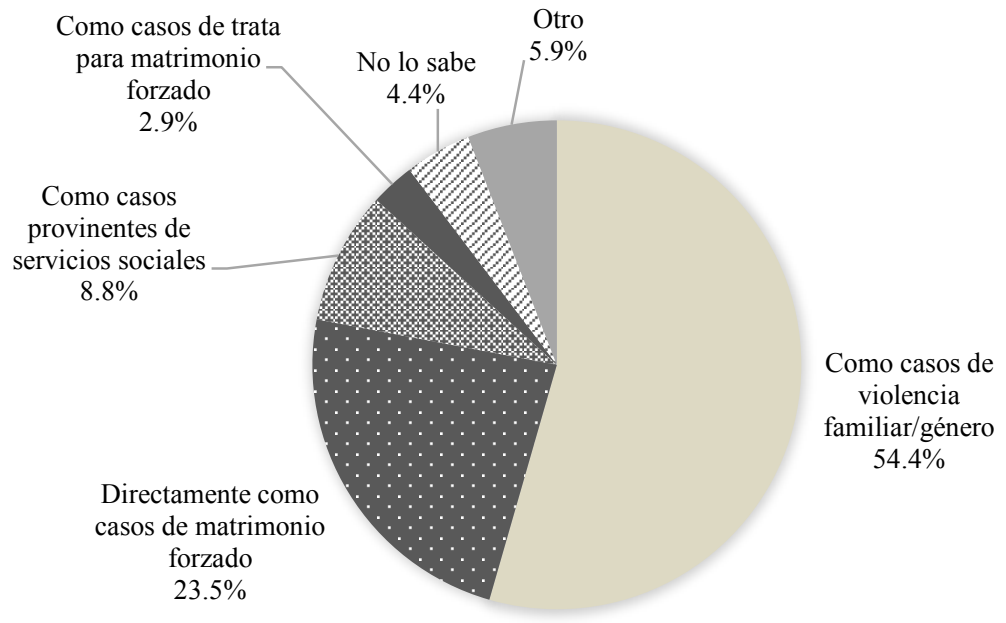

Figura 11: Cómo llegan los hechos a conocimiento de la entidad

Circunstancias en que los casos llegan a conocimiento de las entidades

Llegando la mayor parte de supuestos a conocimiento de las entidades como casos de violencia de género, se constata que, en cuanto al momento en el que afloran, les llegan más cuando las víctimas han contraído matrimonio que cuando están en riesgo de contraerlo (vid. Figura 12). Al preguntar a las entidades si cuando los hechos llegaban a su conocimiento las víctimas había ya contraído matrimonio o se hallaban en riesgo de contraerlo, indicaron, aunque en un porcentaje no sustancialmente superior, que más víctimas habían contraído matrimonio que hallarse en riesgo de contraerlo. 


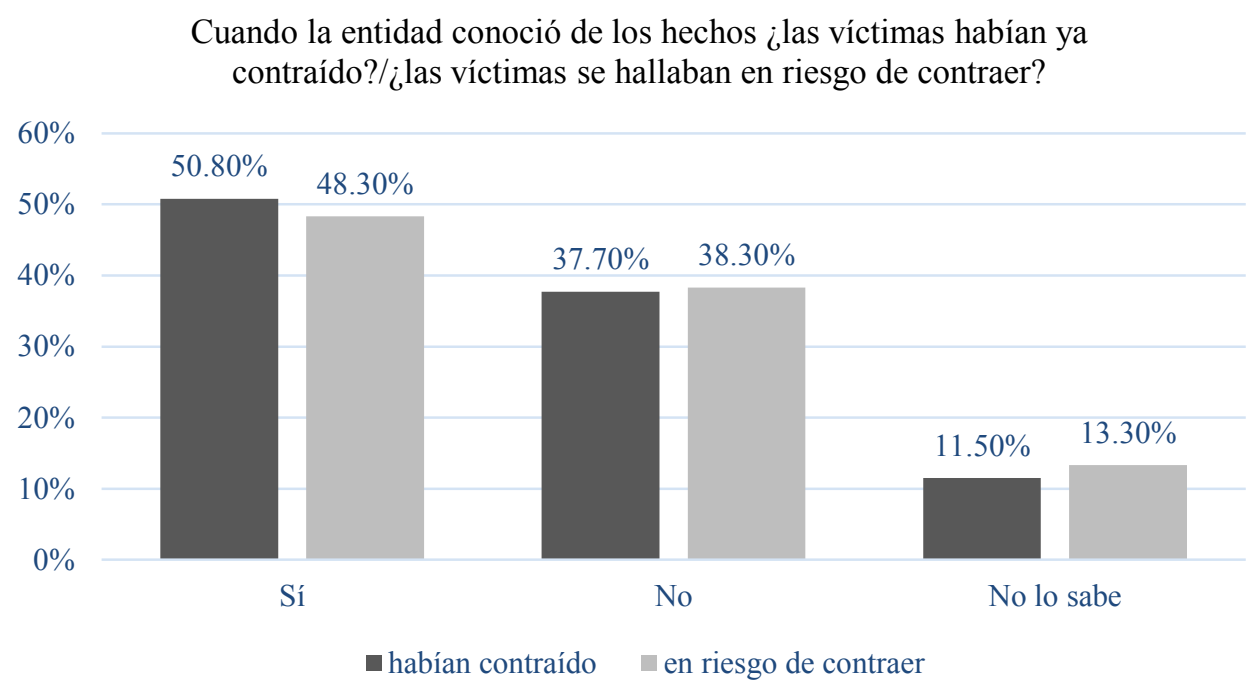

Figura 12: Cuándo llegan los hechos a conocimiento de la entidad

Precisamente, los hechos llegan más a conocimiento de las entidades más efectivas en la detección de supuestos de matrimonio forzado cuando son matrimonios ya contraídos que cuando las víctimas se hallan en riesgo de contraer. En número de entidades, de las dedicadas a asistencia a víctimas de violencia de género y familiar, 20 indicaron que alguna de las víctimas identificadas había ya contraído frente a 18 que dijeron que se hallaban en riesgo de hacerlo. En las dedicadas a la asistencia de víctimas de trata de seres humanos, las respuestas fueron de 15 frente a 10 respectivamente y de las dedicadas a la asistencia a víctimas de matrimonios forzados, las respuestas fueron de 14 frente a 11.

Agrupando la variable relativa a quién pone los hechos en conocimiento de la entidad, se objetivó como esto lo hacían en primer término las víctimas (63.6\%), siendo seguidas por terceras personas (docentes, conocidos o amigos) (29.9\%) y relegando a un tercer puesto los supuestos en que los hechos eran puestos en conocimiento de la entidad por los familiares (3.9\%) (Figura 13). 


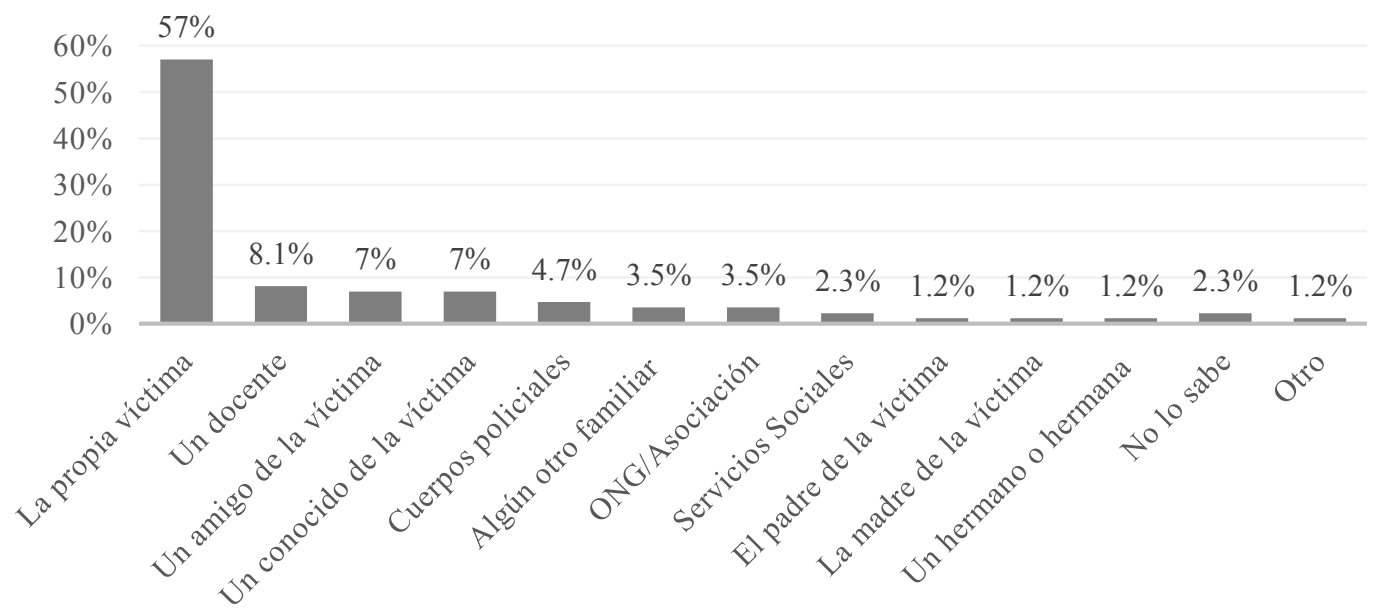

Figura 13: ¿Quién puso los hechos en conocimiento de la entidad?

Situación de la víctima identificada al solicitar asistencia a las entidades

Comenzando por la edad de las víctimas identificadas en el momento de buscar asistencia, los resultados de la investigación (vid. supra Figura 3) muestran como las víctimas eran mayores en el momento de intervenir la entidad que en el momento de contraer matrimonio. Poco más del $23 \%$ de víctimas identificadas eran menores al intervenir la entidad, superando los 18 años el 77\% restante e, incluso, superando los 25 años casi el 27\% de estas mujeres.

Respecto de la situación familiar de las víctimas identificadas en el momento de intervención de la entidad, la mayor parte de estas estaban solteras, probablemente porque no llegaron a contraer matrimonio, si bien el segundo grupo más numeroso era el de las casadas, presumiblemente también en este supuesto porque llegaron a contraer (vid. figura 14). Pese a no existir una relación estadísticamente significativa $(\chi 2(9, N=57)=19.28$; $\rho=.023 ; \Phi=.339$ ), cuanto más jóvenes eran las víctimas en el momento de ser prometidas en matrimonio, menos habitual resultaba que se hallasen casadas en el momento de intervenir la entidad, lo que hace pensar que se consumaron más los matrimonios de mujeres mayores de edad que los de menores antes de la intervención de la entidad. 


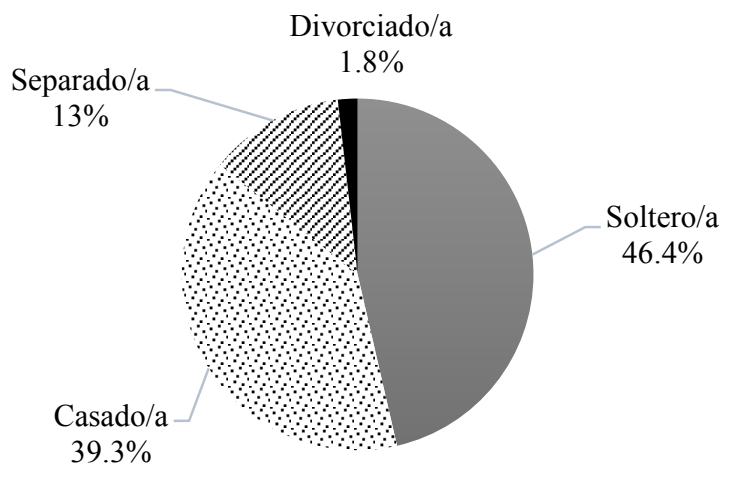

Figura 14: Estado civil de la víctima identificada en el momento de intervención de la entidad

Además, según informaron las propias entidades, la mayor parte de mujeres que acudieron a las mismas no tenían hijos a su cargo al acudir en busca de asistencia (67,9\%), aunque el 32,1\% sí los tenía. Respecto de la tenencia de hijos en ese momento, sí se demostró que la edad al contraer correlacionaba positivamente con significación estadística, de forma que cuanto más joven era la mujer al ser prometida o dada en matrimonio, menos probable era que tuviera hijos al intervenir la entidad $(\chi 2(3, N=57)=15.97 ; \rho=.001 ; \Phi=.534)$.

Finalmente, la mayor parte de las que solicitaron este auxilio eran residentes legales en España en el momento de solicitar la intervención de la entidad (53,6\%) cuando no directamente nacionales españolas (21.4\%) (Figura 15). El análisis bivariante de esta variable con la correspondiente a la edad al contraer mostró la tendencia a ser prometidas o dadas en matrimonio siendo más mayores aquellas mujeres que tenían nacionalidad o residencia legal en España, si bien la correlación carece de significación estadística $(\chi 2(9, N=57)=10.78$; $\rho=.291 ; \Phi=.253)$. 


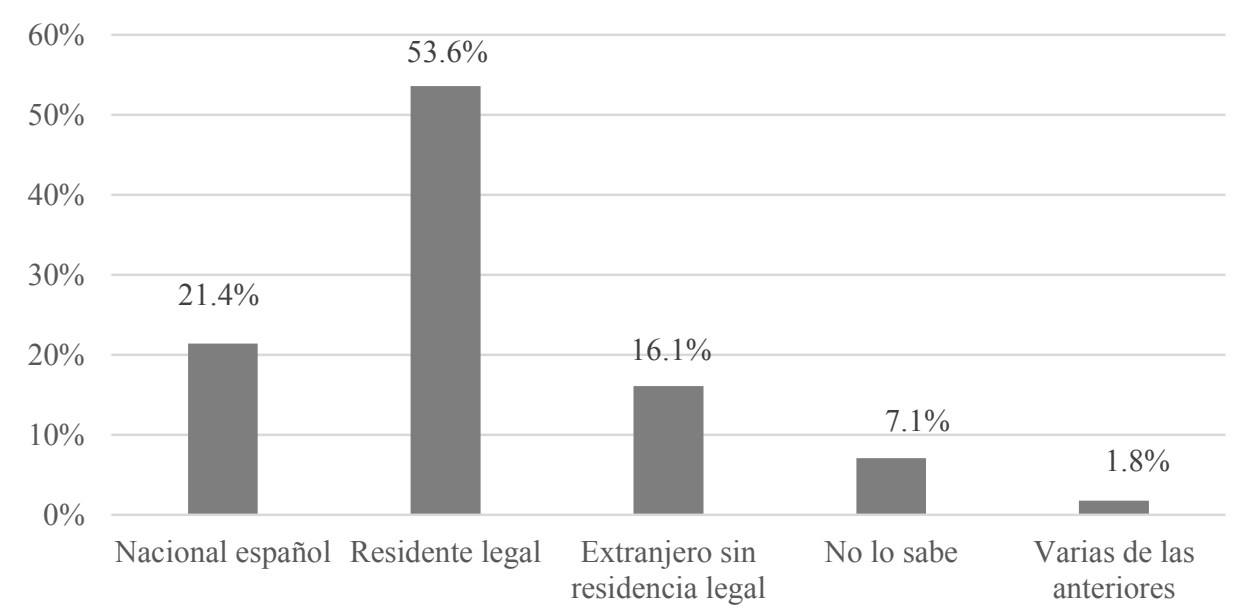

Figura 15: Situación legal de la víctima identificada en el momento de intervención de la entidad

Efectuada la correspondiente correlación de variables para determinar las que tienen mayor relevancia explicativa en orden a posibilitar que estos hechos afloren, se observa como son la nacionalidad de la víctima y la situación legal de la misma en el momento intervenir la entidad las más relevantes.

\section{Discusión}

La investigación expuesta en las páginas que preceden ha permitido confirmar que también en España existen víctimas de matrimonios forzados. Concretamente, se han identificado un mínimo de 57 víctimas con las que las entidades asistenciales encuestadas han intervenido.

Respecto del segundo de los objetivos de la investigación, establecer un perfil de las víctimas identificadas que padecen estos procesos, este se elaboró a partir de la información proporcionada por las entidades asistenciales, siguiendo la metodología recomendada por la propia Agencia de los Derechos Fundamentales de la Unión Europea (FRA, 2014) y empleada por otras investigaciones en países de nuestro entorno (Tahirih Justice Centre, 2011; Mirbach, 2011; Kazimirski, 2009). Pese a lo reducido de la muestra y al hecho de haber sido seleccionada por las entidades asistenciales, puede indicarse que las personas en riesgo de ser victimizadas son mujeres muy jóvenes -menores de 21 años- o incluso menores de

\section{Revista Española de Investigación Criminológica}


edad, por lo que suelen hallarse todavía a cargo de sus padres o adultos de referencia. Este hallazgo resulta coherente con los trabajos que subrayan el importante sesgo de género en la práctica del matrimonio forzado (FRA, 2014; Hester et al. 2007; Psalia et al., 2016) así como la minoría de edad o juventud de las víctimas (Gangoli \& Chantler, 2009; Kazimirski, 2009; Mirbach et al., 2011).

Al margen del sexo y la edad de las víctimas, atendida la relación establecida en cierto discurso político-criminal entre el matrimonio forzado y la pertenencia a determinadas minorías étnicas, culturales, religiosas e incluso nacionales (Anitha \& Gill, 2011b; Chantler et al., 2009), se preguntó a las entidades por la nacionalidad de la víctima, su comunidadetnia de pertenencia y la religión que profesaban. Los resultados alcanzados muestran que se trata de mujeres que generalmente proceden del Magreb, África Subsahariana o Asia Central, y también, si bien en menor porcentaje, de etnia gitana. Asimismo, en un porcentaje nada desdeñable tienen nacionalidad española y profesan mayoritariamente la religión musulmana. El referido perfil no se adecua al discurso político y mediático que vincula este proceso exclusivamente con determinadas minorías culturales de migrantes. La evidencia de que existen víctimas con nacionalidad española y con residencia legal en España aproxima los resultados aquí obtenidos a los de las investigaciones que relativizan la influencia de factores étnicos o religiosos (Chantler et al., 2009; Kazimirski, 2009) y que, por el contrario, subrayan la vinculación entre el matrimonio forzado y estructuras familiares patriarcales (Anitha \& Gill, 2011b; Gangoli et al., 2011). Con todo, las variables con más peso en punto a explicar la victimización son, en nuestro trabajo, la nacionalidad, la religión y la comunidad/etnia de la víctima.

En relación con las dinámicas propias de estos procesos, se constata como habitualmente se emplean mecanismos de forzamiento de la voluntad de las víctimas para contraer de baja intensidad, sutiles o envolventes, relacionados con la pertenencia de las víctimas a determinadas comunidades, puesto que consisten mayoritariamente en el recurso a la presión familiar o al apego a la tradición. Pese a que pudiera parecer que los medios empleados pueden venir determinados por la edad de la víctima en el momento de contraer o ser prometidas en matrimonio, lo cierto es que no se ha constatado dicha relación, aun cuando sí se ha mostrado que los medios usados respecto de las víctimas menores son más

Revista Española de Investigación Criminológica 
sutiles que aquellos a los que se recurre con víctimas mayores de edad, en que se emplea más a la amenazada.

Queda relegado a un claro segundo término el empleo de medios comisivos más incisivos, como la intimidación, la violencia y el engaño, que son los únicos que contempla el delito de matrimonios forzados introducido en el CP y que se aplican más a víctimas más mayores y de nacionalidad española o que se encuentran en situación de residencia legal en España. El matrimonio acostumbra a celebrarse en el país de origen de la familia de la víctima, salvo que se trate de víctimas de nacionalidad española, en cuyo caso se celebra mayoritariamente en España. Se desconoce, sin embargo, si en este último supuesto la finalidad de la operación es la de imponer un cónyuge dentro de la propia comunidad a la que pertenece la víctima o si se emplea también como herramienta para soslayar los restrictivos requisitos para obtener la residencia en territorio español.

Finalmente, en relación a cómo afloran estos procesos de victimización en un ámbito asistencial, las entidades que han reportado un mayor número de casos identificados han sido las dedicadas asistir a víctimas de violencia familiar y de género, de trata de seres humanos y de matrimonios forzados, además de aquellas que tienen el matrimonio forzado como objetivo prioritario. Este extremo refuerza la idea relativa a la necesidad de contar con profesionales formados y capacitados en el seno de las entidades para detectar supuestos de victimización, en coherencia con lo puesto de manifiesto en otras investigaciones, por ejemplo, en el ámbito de la trata de seres humanos (Farell \& Pfeffer, 2014; Renzetti, Bush, Castellanos \& Hunt, 2015). Los hechos se ponen en conocimiento de las entidades más cuando son matrimonios ya contraídos que cuando están por contraer, lo que pone de manifiesto un déficit de mecanismos para la detección preventiva de este fenómeno que permita una intervención anticipada. Además, acostumbran a ser revelados o denunciados por las propias víctimas o por terceros, raramente por miembros del núcleo familiar de la contrayente. Junto a lo indicado, los resultados de la investigación ponen de manifiesto que las víctimas identificadas no acuden en busca de ayuda en el momento de producirse los hechos, sino en un momento posterior, cuando se hallan en una situación personal y familiar de cierto empoderamiento que se concreta en ser mayores de edad, sin hijos a su cargo y teniendo nacionalidad española o residencia legal en España, siendo estas dos últimas

\section{Revista Española de Investigación Criminológica}


circunstancias las que explican en mayor medida que se dirijan a entidades asistenciales en solicitud de apoyo. En definitiva, los resultados de esta investigación apuntan a que el matrimonio forzado es una práctica consentida si no impulsada por las familias de las víctimas que en la mayor parte de supuestos llegan a conocimiento de las entidades asistenciales cuando las víctimas se hallan en situación personal y familiar de cierto empoderamiento. A sensu contrario, las mujeres que siguen unidas en matrimonio, con hijos a su cargo y en situación de irregularidad residencial, no sólo probablemente no denunciarán los hechos, sino que quizá ni siquiera acudirán a entidades asistenciales en busca de apoyo.

Ante tal situación, el solo recurso al Derecho penal para abordar esta realidad, lejos de erradicarla, puede contribuir a invisibilizarla, evitando que los procesos de victimización padecidos por estas mujeres afloren. Esto no solo porque con la introducción del art. 172 bis $\mathrm{CP}$ se ha creado un delito superfluo, privilegiante, altamente simbólico y otrizante de determinadas culturas, sino porque tipifica el empleo de medios comisivos poco empleados en estos procesos y, sobre todo, porque coloca a las víctimas en la encrucijada de tener que separarse de su comunidad de origen para obtener tutela institucional.

Frente a esta opción, un abordaje más interseccional de la respuesta jurídica al matrimonio forzado debería tomar en consideración todas las variables que pueden explicar los procesos de victimización y discriminación a que pueden verse sometidas estas mujeres (Anitha \& Gill, 2011a; Kool, 2012; Phillips \& Dustin, 2004). Tal aproximación debería conducir a incidir en estrategias de prevención secundaria de la victimización orientadas a los grupos de riesgo, así como a la formación de profesionales capacitados para detectar estas situaciones. Paralelamente, el diseño de mecanismos jurídicos de protección de las víctimas debería ensayar soluciones que no pasasen necesariamente por el empleo del sistema de justicia, por ejemplo, implementando órdenes de protección de naturaleza civil. Incluso en los casos en que el recurso al sistema de justicia penal se estimase preciso, sería deseable otorgar preferencia al empleo de mecanismos de justicia restaurativa que no obligasen a las víctimas a dirigir procesos penales contra familiares en ocasiones muy próximos para obtener tutela penal y que además fuesen capaces de provocar un vuelco en la forma en que los infractores afrontan esta realidad (Meléndez, 2018). 


\section{Limitaciones de la investigación}

La metodología empleada muestra dos limitaciones fundamentales a las que debe atenderse a la hora de valorar los resultados de esta investigación. De un lado, la dificultad de acceder directamente a víctimas de matrimonio forzado, derivada de la dificultad de contacto con cualquier tipo de víctima, a lo que en el caso de los matrimonios forzados se añade el escaso conocimiento que existe todavía sobre esta realidad en España. Esto ha provocado que el acceso a la información sobre dichas víctimas haya sido a través de entidades asistenciales que eventualmente pueden haberlas asistido, con lo que los datos sobre víctimas expuestos no proceden directamente de estas, sino de las entidades que los han proporcionado, sin que conste, además, si las entidades disponían de información relativa a más supuestos ni los criterios empleados para la selección de los casos informados en las fichas.

De otro lado, el porcentaje de respuesta de los cuestionarios electrónicos no ha sido elevado, como acostumbra a suceder con otras investigaciones que emplean dicha metodología. Las razones que en este concreto caso han explicado la baja incidencia en la respuesta inicial a dicho cuestionario han sido de tres tipos. De un lado, el cuestionario se enviaba desde una dirección de correo electrónico Gmail que no era la oficial de la universidad que coordinaba la investigación, con lo que algunos receptores pudieron no identificar el envío como correspondiente a una investigación oficial pese a que lo acompañase un mensaje de presentación. De otro, se han identificado dificultades técnicas de algunos encuestados para acceder al cuestionario porque determinados servidores oficiales no permiten acceder a determinadas webs como aquella desde la que se remitía el cuestionario. Finalmente, en ocasiones se ha evidenciado que el receptor del mismo dentro de la institución no era la persona más adecuada para cumplimentarlo, sino el titular de la dirección de correo electrónico que aparecía como contacto en la web de la institución rastreada para confeccionar la base de datos. La confirmación de tales limitaciones determinó el cambio de metodología que condujo a contactar primero telefónicamente a las entidades a las que después se remitió el cuestionario online. Con todo, la muestra real asciende a 150 entidades, con lo que resulta de dimensiones reducidas para efectuar inferencias. 


\section{Referencias}

Anitha, S. \& Gill, A. (2011a). Reconceptualising consent and coercion within an intersectional understanding of forced marriage. Gill, A.K. \& Anitha, S. (Eds.) (2011). Forced Marriage. Introducing a social justice and human rights perspective. London and New York: Zed Books.

Anitha, S. \& Gill, A. (2011b). The social construction of forced marriage and its "victim" in media coverage and crime policy discourses. Gill, A.K. \& Anitha, S. (Eds.) (2011). Forced Marriage. Introducing a social justice and human rights perspective. London and New York: Zed Books.

Chantler K., Gangoli, G. \& Hester, M. (2009). Forced marriage in the UK: Religious, cultural, economic or state violence? Critical Social Policy, 29 (4). DOI: $10.1177 / 0261018309341905$.

European Agency for Fundamental Rights (FRA) (2014). Addressing forced marriage in the EU. Legal provisions and promising practices. Luxemburg: Publications Office of the European Union.

Farrell, A. \& Pfeffer, R. (2014). Policing Human Trafficking: Cultural Blinders and Organizational Barriers, The Annals of the American Academy of Political and Social Science 653, 46-64. DOI: 10.1177/0002716213515835.

Forced Marriage Unit (FMU) (2016). Statistics on forced marriage for 2016. Disponible en: https://www.gov.uk/government/statistics/forced-marriage-unit-statistics-2016.

Gangoli, G. \& Chantler, K. (2009). Protecting victims of forced marriage: is age a protective factor? Feminist Legal Studies 17 (3), 267-288. DOI: 10.1007/s10691-009-9132-7.

Gangoli, G., McCarry, M. \& Razak, A. (2009). Child marriage or Forced marriage: South Asian Communities in North East England, Children and Society, 23. DOI:10.1111/j.1099-0860.2008.00188.x.

Gangoli, G., Chantler, K, Hester, M. \& Singleton, A. (2011). Understanding forced marriage: definitions and realities. Gill, A. K \& Anitha, S. (Eds.), Forced Marriage, Introducing a Social Justice and Human Rights Perspective. London and New York: Zed Books.

Hamel, C. (2011). Immigrées et filles d'immigrés: le recul des mariages forces. Population \& Sociétés 479, 1-4.

Hester, M., Chantler, K., Gangoli, G., Devgon, J., Sharma, S. \& Singleton, A. (2007). Forced marriage: the risk factors and the effect of raising the minimum age for a sponsor, and of leave to enter the UK as a spouse or fiancé(e). Final Report. Bristol.

Igareda, N. (2015). Matrimonios forzados: ¿otra oportunidad para el Derecho Penal simbólico? Indret 1/2015, 1- 18.

Igareda, N., Barcons, M., Lotti, M. \& Leye, E. (2016). Matrifor. Approaching forced marriages as a new form of trafficking in human beings in Europe. Brussels: European Commission.

Revista Española de Investigación Criminológica

Artículo 4, Número 17 (2019)

www.criminologia.net

ISSN: 1696-9219 
Kazimirski, A., Keogh, P., Kumari, V., Smith, R., Gowland, S., Purdon, S. \& Khanum, N., (2009). Forced Marriage- Prevalence and Service Response. National Centre for Social Research, Research Report No DCSF-RR128.

Khanum, N. (2008). Forced marriage, family cohesion and community engagement: national learning through a case study of Luton. Wartford: Equality in Diversity.

Kool, R. (2012). Step forward, or forever hold your peace: penalizing forced marriages in the Netherlands. Netherlands Quarterly of Human Rights 201, vol.30/4, 1-22.

Maqueda Abreu, M. (2016). El hábito de legislar sin ton ni son. Una lectura feminista de la reforma penal de 2015. Cuadernos de Política Criminal 118, 5-42.

Martínez, R., \& Lee, M. (2004). Inmigración y delincuencia. Revista Española De Investigación Criminológica, 2, 1-34.

Meléndez, A. (2018). El papel de la mediación penal en el proceso de cambio del infractor. Revista Española De Investigación Criminológica, 16, 1-24.

Mirbach, T., Schaak, T. \& Triehl, K. (2011). Zwangsheiratungen in Deutschland-Anzahl und Analyse von Beratungsfällen. Wissentschaftliche Untersuchung im Auftrag des Bundesministeriums für Familie, Senioren, Frauen und Jugend. Disponible en: https://www.bmfsfj.de/bmfsfj/service/publikationen/zwangsverheiratung-indeutschland---anzahl-und-analyse-von-beratungsfaellen/80740.

Phillips, A. \& Dustin, M. (2004). UK initiatives on forced marriage: regulation, dialogue and exit. Political Studies 52 (3), 531-551. DOI: 10.1111/j.1467-9248.2004.00494.x.

Psalia, E., Leigh, V., Verbari, M., Fiorentini, S., Dalla Pozza, V. \& Gomez, A. (2016). Forced Marriage from a gender perspective, Study for the Femm Committee, Directorate General for Internal Policies. Brussels: European Parliament.

Renzetti, C., Bush. A., Castellanos, M. \& Hunt, G. (2015). Does training make a difference? An evaluation of a specialized human trafficking training module for law enforcement officers. Journal of Crime and Justice, Vol. 38, No. 3, 334-350. DOI: 10.1080/0735648X.2014.997913.

Rude-Antoine, E. (2007). Les marriages forces: Enquête sur les legislations et les actions politiques en Europe. Critique Internationale 34(1), 89-101.

Sabbe, A., Temmerman, M., Bremse, E. \& Leye, E. (2014). Forced marriage: an analysis of legislation and political measures in Europe. Crime, Law and Social Change 62 (2), 171-189. DOI: 10.1007/s10611-014-9534-6.

Sharp, N. (2008) Forced marriage in the UK: A scoping study on the experience of women from Middle Eastern and North East African Communities. London Refugee. www.refuge.org.uk.

Tahirih Justice Centre (2011). Forced marriage in immigrant communities in the United States. National Survey Results. Disponible en: http://www.tahirih.org/pubs/forcedmarriage-in-immigrant-communities-in-the-united-states/ 
Trama di Terre (2014). Matrimoni forzati, combinati e precoci. Vademecum per operatore e operatrici. Disponible en: http://informa.comune.bologna.it/iperbole/media/files/violenza_contro_donne_vade mecum_matrimoni_forzati_2014.pdf.

Torres Rosell, N. (2015). Matrimonio forzado: aproximación fenomenológica y análisis de los procesos de incriminación. Estudios Penales y Criminológicos XXXV, 831-917.

Trapero Barreales, M. (2016). Matrimonios ilegales y Derecho Penal. Valencia: Tirant lo Blanch.

United Nations Children's Fund (2001). Innocenti Digest no.7: Matrimonios prematuros. New York: UNICEF.

United Nations Children's Fund (2008). Child marriage and the Law, Legislative Reform Initiative Paper Series. New York: Division of policy and planning, UNICEF.

United Nations Children's Fund (2014). Ending Child marriage. Progress and prospects. New York: UNICEF.

Villacampa Estiarte, C. (2018). Política criminal española en materia de violencia de género. Valoración crítica. Valencia: Tirant lo Blanch.

\section{Agradecimientos}

Agradecemos a las siguientes personas, que nos han ayudado en la fase de recogida de datos y en el tratamiento estadístico de los mismos, su inestimable colaboración: Alejandra Pujols Pérez, M. Jesús Gómez Adillón, Claudia Torres y Laura Serramià.

\section{Financiación}

Este trabajo ha sido financiado con cargo al proyecto "Formas contemporáneas de violencia de género: mecanismos jurídicos de protección de las víctimas" (I+D DER2015-64506-C2$1-\mathrm{R})$.

Carolina Villacampa es Catedrática de Derecho Penal de la Universitat de Lleida. Dirige el Máster Oficial Interuniversitario en Sistema de Justicia Penal y es miembro del Grupo de Investigación en Sistema de Justicia Penal. En los últimos años sus principales líneas de investigación se han centrado en los derechos de las víctimas, la violencia de género y la trata de seres humanos.

(iD https://orcid.org/0000-0002-1791-8788

Núria Torres es Profesora Agregada Serra Hunter de Derecho Penal en la Universitat Rovira i Virgili (Tarragona). Coordina en su universidad el Máster Oficial Interuniversitario en Sistema de Justicia Penal. Entre sus principales áreas de interés científico se cuentan la tutela de las víctimas, la violencia de género y las penas de cumplimiento en la comunidad.

iD https://orcid.org/0000-0002-2893-1267 